\title{
Self-Synergistic Effect of Ethylene-Heptane Mixture on Soot Formation
}

\author{
Liang QIU, Xiao-bei CHENG*, and Zhong-qiu LI
}

Huazhong University of Science and Technology, Wuhan, Hubei, People's Republic of China.

Tel: +86-027-87543458 Email: xbcheng@hust.edu.cn

Keywords: ethylene; heptane; soot volume fraction; opposed-flow flame; self-synergistic effect. Abstract. The combustion and soot formation process of ethylene-heptane mixture was numerical calculated in an opposed-flow flame by an improved kinetic mechanism. The mechanism contains 211 species and 1410 reactions, including the pyrolysis reactions of heptane, core reactions of C0-C4, the formation of benzene, PAH growth up to coronene (A7). This mechanism was well validated by the mole fraction of major species in a heptane premixed flame and aromatic species in an ethylene/air opposed-flow flame. Numerical simulation in ethylene-heptane opposed-flow diffusion flame shows a self-synergistic effect on soot formation. As the ratio of heptane increases, the soot volume fraction (SVF), soot number density (SND), peak mole fraction of benzene and key PAH species all increase first and then decrease. A maximum peak of SVF and SND is reached when 5\% heptane is added to the fuel. Propyl and methyl play important roles in the synergistic effect of the formation of benzene.

\section{Introduction}

Opposed-flow flames are generally used to investigate the soot characteristics. There are two types of the opposed-flow flame, soot formation (SF) flame and soot formation and oxidation (SFO) flame [1]. The flame plane of the SF flame is located on the oxidizer side, while the other located on the fuel side. In SF flame, PAHs and soot are generated in the fuel side of the flame, and the soot particles move away from the high-temperature reacting region. So the oxidation of soot and PAH does not occur in this case. Therefore, SF flame is a good choice to study the growth of PAH and soot particles. However, there are also some researches studies on SFO flames where the oxidation of PAH and soot needs to be considered.

Fuel structure plays an important role in the process of the formation and development of PAH and soot [2]. Many researchers investigated the effects of the fuel structure on soot formation process in diffusion flame by fuel mixing, and observed the synergistic effect on PAH and soot formation in some experiments [3-8]. The synergistic effect in the process of soot formation process is defined as the case when a mixture fuel can produce more PAH and soot as compared to the respective pure fuels.

Synergistic effects on soot formation are observed in many fuel mixing experiments, however, little of them are carried on liquid fuels. Heptane is abundant in both gasoline and diesel fuel [9], and is used as a preference fuel in the numerical calculation of engine combustion. Ethylene is an important intermediate product in the heptane high temperature $\beta$-scission process. Therefore, the synergistic effect of ethylene-heptane mixture can also be treat as the self-synergistic effect on continuous heptane diffusion combustion. In this research, the soot formation process of ethylene-heptane binary mixture was numerical calculated in an opposed-flow diffusion flame. The distribution of SVF, SND, core species, A1 and PAHs were displayed. The mechanism of synergistic effects on soot, A1 and PAHs were analyzed in detail.

\section{Kinetic mechanism and simulated conditions}

kinetic mechanism

In this work, premixed flame and opposed-flow diffusion flame were simulated by PREMIX code and OPPDIF code in CHEMKIN III [10], respectively. $\mathrm{C}_{2} \mathrm{H}_{4}$ is an intermediate product in the pyrolysis of 
$\mathrm{nC}_{7} \mathrm{H}_{16}$, thus the mechanism established in this work is actually the expanded $\mathrm{nC}_{7} \mathrm{H}_{16}$ mechanism, though the target fuel is $\mathrm{C}_{2} \mathrm{H}_{4}-\mathrm{nC}_{7} \mathrm{H}_{16}$ binary mixture. The improved mechanism contains 211 species and 1410 elementary reactions, including the pyrolysis reactions of heptane, core reactions of $\mathrm{C} 0-\mathrm{C} 4$, the formation of benzene, and PAH growth up to coronene (A7). In order to reduce the computational time, the reduced heptane pyrolysis mechanism was taken from [11], which contains 59 elementary reactions. USC 2.0 [12], with 111 species and 784 reactions, was used as the mechanism of core reactions of $\mathrm{C} 0-\mathrm{C} 4$ and formation of benzene.

Table 1 Key reactions of the mechanism

\begin{tabular}{l|l|l|l}
\hline Number & Reaction & Number & Reaction \\
\hline R1 & $\mathrm{pC}_{3} \mathrm{H}_{4}+\mathrm{C}_{3} \mathrm{H}_{3}=\mathrm{A} 1+\mathrm{H}$ & $\mathrm{R} 8$ & $\mathrm{C}_{6} \mathrm{H}_{5} \mathrm{CH}_{3}+\mathrm{H}=\mathrm{A} 1+\mathrm{CH}_{3}$ \\
\hline R2 & $\mathrm{aC}_{3} \mathrm{H}_{4}+\mathrm{C}_{3} \mathrm{H}_{3}=\mathrm{A} 1+\mathrm{H}$ & $\mathrm{R} 9$ & $\mathrm{C}_{3} \mathrm{H}_{3}+\mathrm{C}_{3} \mathrm{H}_{3}=>\mathrm{A} 1$ \\
\hline R3 & Fulvene $=\mathrm{A} 1$ & $\mathrm{R} 10$ & $\mathrm{~A} 1-+\mathrm{CH}_{3}=\mathrm{C}_{6} \mathrm{H}_{5} \mathrm{CH}_{3}$ \\
\hline R4 & Fulvene $+\mathrm{H}=\mathrm{A} 1+\mathrm{H}$ & $\mathrm{R} 11$ & $\mathrm{C}_{6} \mathrm{H}_{5} \mathrm{CH}_{2}+\mathrm{H}(+\mathrm{M})=\mathrm{C}_{6} \mathrm{H}_{5} \mathrm{CH}_{3}(+\mathrm{M})$ \\
\hline R5 & $\mathrm{C}_{3} \mathrm{H}_{3}+\mathrm{aC}_{3} \mathrm{H}_{5}=$ Fulvene $+2 \mathrm{H}$ & $\mathrm{R} 12$ & $\mathrm{C}_{6} \mathrm{H}_{5} \mathrm{CH}_{2}+\mathrm{H}=\mathrm{A} 1-+\mathrm{CH}_{3}$ \\
\hline R6 & $\mathrm{C}_{5} \mathrm{H}_{6}+\mathrm{C}_{2} \mathrm{H}_{3}=\mathrm{A} 1+\mathrm{CH} \mathrm{H}_{3}$ & $\mathrm{R} 13$ & $\mathrm{C}_{6} \mathrm{H}_{5} \mathrm{CH}_{3}+\mathrm{H}=\mathrm{C}_{6} \mathrm{H}_{5} \mathrm{CH}_{2}+\mathrm{H}_{2}$ \\
\hline R7 & $\mathrm{C}_{5} \mathrm{H}_{5}+\mathrm{CH}_{3}=\mathrm{A} 1+2 \mathrm{H}$ & $\mathrm{R} 14$ & $\mathrm{C}_{2} \mathrm{H}_{4}+\mathrm{CH}_{3}=\mathrm{n}-\mathrm{C}_{3} \mathrm{H}_{7}$ \\
\hline
\end{tabular}

According to the suggestion of Jin et al. [13], the reaction between $\mathrm{C}_{3} \mathrm{H}_{3}$ and the isomer of $\mathrm{C}_{3} \mathrm{H}_{4}$ $\left(\mathrm{pC}_{3} \mathrm{H}_{4}, \mathrm{aC}_{3} \mathrm{H}_{4}\right)$, the isomerization of fulvene $\left(\mathrm{C}_{5} \mathrm{H}_{4} \mathrm{CH}_{2}\right)$ are also important paths to form benzene (A1). Fulvene can be obtained from the reaction between $\mathrm{C}_{3} \mathrm{H}_{3}$ and $\mathrm{aC}_{3} \mathrm{H}_{5}$ through $\mathrm{R} 4$, as shown in Table 1 (R1-R5). Slavinskaya et al. [14] suggested that the reaction between $\mathrm{C}_{5} \mathrm{H}_{6}$ and $\mathrm{C}_{2} \mathrm{H}_{3}$, and the reaction between $\mathrm{C}_{5} \mathrm{H}_{5}$ and $\mathrm{CH}_{3}$ should be included in the formation mechanism of $\mathrm{A} 1$, as show in Table 1 (R6, R7). The detailed sub-mechanism of $\mathrm{C}_{5} \mathrm{H}_{5}$ is taken from [15]. KM2 (KAUST PAH mechanism 2) [16] up to coronene (A7) was adopted to calculate the PAH formation. According to [8], the nucleation of soot is both the homogeneous and heterogeneous reactions with 8 different PAHs. Since bigger PAHs are more likely to form soot, A4 is treat as the smallest nucleation species, and A7 is the biggest one. The aliphatic chain is also included in the nascent soot based on the experiment results reported by Skeen et al. [17].

In this investigation, the surface growth is calculated by the ABF mechanism [18] based on HACA path. Assume there is no gas species forms in the nucleation process [19], the number of soot particles remains unchanged. The dynamics of soot particle are described by particle balance equation, and solved by method of moments [20], then the soot volume fraction can be obtained.

\section{Simulated conditions}

In the first part, the improved mechanism is validated by the mole fraction of major species in a heptane premixed flame (PF1) and aromatic species in an ethylene/air opposed-flow flame (OF1). The calculated results are compared with the experiments data reported by Bakali et al. [21], and Olten et al. [22], respectively. In the second part, the combustion of ethylene-heptane binary fuel mixture was calculated in an opposed-flow flame (OF2) to predict and analysis the formation trend of soot volume fraction (SVF), soot number density (SND), benzene and some key PAH species. The calculated conditions of premixed flame and opposed-flow flames were described in [21] and [22] respectively.

The initial mole fraction of fuel in OF2, with a separate distance of $0.8 \mathrm{~cm}$, under different cases are listed in Table 2. Heptane ratio $(\beta)$ is defined as the ratio of the volumetric flow rate of heptane to that of the total fuel. Inlet velocity of fuel and oxidizer is $20 \mathrm{~cm} / \mathrm{s}$, and the inlet temperature is $300 \mathrm{~K}$.

Table 2 Initial fuel concentration in OF2.

\begin{tabular}{|c|c|c|c|c|c|c|c|c|c|c|c|c|c|}
\hline \multicolumn{2}{|c|}{ Case } & 01 & 02 & 03 & 04 & 05 & 06 & 07 & 08 & 09 & 10 & 11 & 12 \\
\hline \multicolumn{2}{|r|}{$\beta$} & 0.000 & 0.025 & 0.050 & 0.075 & 0.100 & 0.150 & 0.200 & 0.300 & 0.400 & 0.550 & 0.700 & 1.000 \\
\hline \multirow{3}{*}{ Fuel } & $\mathrm{Ar}$ & \multicolumn{12}{|c|}{0.250} \\
\hline & $\mathrm{C}_{2} \mathrm{H}_{4}$ & 0.750 & 0.731 & 0.713 & 0.694 & 0.675 & 0.638 & 0.600 & 0.525 & 0.450 & 0.338 & 0.225 & 0.000 \\
\hline & $\mathrm{nC}_{7} \mathrm{H}_{16}$ & 0.000 & 0.019 & 0.037 & 0.056 & 0.075 & 0.112 & 0.150 & 0.225 & 0.300 & 0.412 & 0.525 & 0.750 \\
\hline
\end{tabular}




\section{Results and discussion}

\section{Validation of the mechanism}

Fig. 1 shows the comparison of simulated results and experimental data from literatures. (a) and (b) presents the mole fraction of the major species in the simulated and experimental heptane premixed flame and the mole fraction of aromatic species in ethylene/air opposed-flow flame, respectively. The discrete points are taken from [21] and [22]. As shown in Fig.1, the simulated results fit well with the experimental data, which indicates the newly coupled mechanism is highly accurate for predicting the distribution of key species.
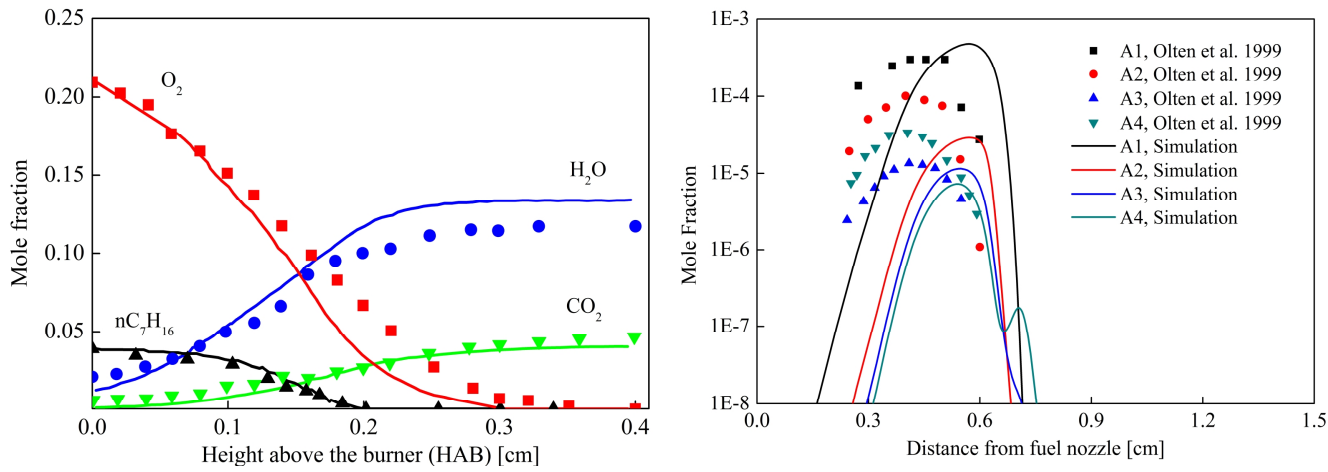

Fig. 1. Comparison of simulated results and experimental data from literatures. (a) the mole fraction of major species in heptane premixed flame, while (b) the mole fraction of aromatic species in ethylene/air opposed-flow flame.

Prediction of synergistic effect in opposed-flow flame

Fig.2 shows the distribution of soot volume fraction (SVF) and soot number density (SND) under different operation conditions. With the increase of $\beta$, the soot forming region moves towards the oxidizer side gradually. Both the peak of SVF and SND increase first and then decrease, and the maximum peak of SVF is reached as $5 \%$ heptane is added (case 03 ) to the fuel, which is $6.3 \%$ higher than case 01 . While at the same case, the peak of SND is almost $20 \%$ higher. In addition, SVF and SND of pure heptane (case12) is much lower than that of other cases. The sooting tendency of alkane is lower than alkene, thus, the synergistic effect is occurred in the soot formation of ethylene-heptane mixture based on its definition. Studies have shown that the product of benzene is the dominated process in soot formation. Therefore, in order to explain the causes of this interesting effect, analysis to the distribution of $\mathrm{A} 1$ and its rate of production (ROP) is needed.
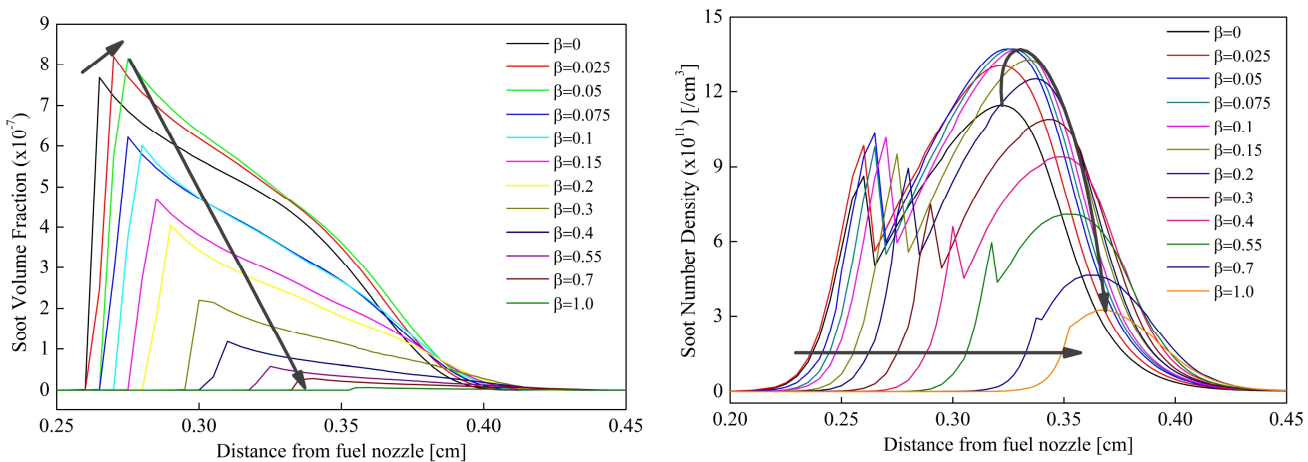

Fig.2 SVF and SND distribution at different conditions. (a) Soot volume fraction(b) Soot number density

Fig. 3 shows the distribution of the mole fraction of A1 at different operation conditions. The formation region of A1 moves towards the oxidizer side gradually with the increase of $\beta$, and finally get across the stagnation plane. The peak of the concentration of A1 increase first and then decrease, and the maximum peak is reached as $10 \%$ heptane (case05) is added to the fuel, which is almost $25 \%$ higher than case 01 . Therefore, Fig. 3 suggests the synergistic effect exists at the formation of A1 in the $\mathrm{C}_{2} \mathrm{H}_{4}-\mathrm{nC}_{7} \mathrm{H}_{16}$ binary mixture flame. As described above, case 01 , case 05 , and case 12 are the three most important cases, for the sake of simplicity, the next analysis is only for these three operating conditions. 


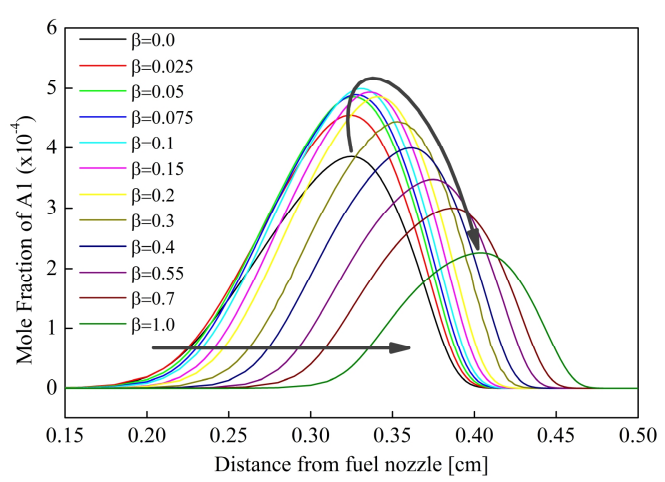

Fig.3 A1 distribution.

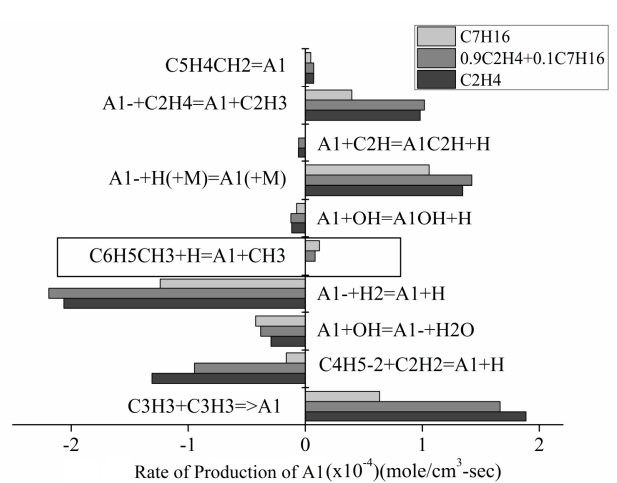

Fig.4. Rate of production analysis of A1.

Fig. 4 shows the ROP of the most important 10 reactions of $A 1$ for these three cases. R 8 does not exist in case 01 , but exists in case 05 and case 12 , and the ROP of R8 in case 12 is slightly higher than that in case 05. Compared with the other two cases, the rate of production and rate of consumption of A1 in case 12 is greatly reduced, and the reaction R9 is the most obvious one. As described in Fig.3, the peak concentration of $\mathrm{A} 1$ in case 05 is almost $25 \%$ higher than that of case 01 , thus $\mathrm{R} 8$ can be considered as the key reaction in the synergistic effect, and $\mathrm{C}_{6} \mathrm{H}_{5} \mathrm{CH}_{3}$ is the key species. Again, the production of $\mathrm{C}_{6} \mathrm{H}_{5} \mathrm{CH}_{3}$ need to be analyzed.

Fig. 5 displays the distribution of $\mathrm{C}_{6} \mathrm{H}_{5} \mathrm{CH}_{3}$ at the three cases. The peak mole fraction of case 05 is two times higher than that of case 01 and case 12 , which means the synergistic effect also exists in $\mathrm{C}_{6} \mathrm{H}_{5} \mathrm{CH}_{3}$.

Fig. 6 represents the ROP of $\mathrm{C}_{6} \mathrm{H}_{5} \mathrm{CH}_{3}$ of these three cases. The most important two reactions that forms $\mathrm{C}_{6} \mathrm{H}_{5} \mathrm{CH}_{3}$ are $\mathrm{R} 10$ and $\mathrm{R} 11$, and from case 01 , case 05 to case 12, the $\mathrm{ROP}$ of $\mathrm{C}_{6} \mathrm{H}_{5} \mathrm{CH}_{3}$ increases first and then decreases. Another obvious trend is that the overlap region between R11 and R10 is getting bigger, and moving towards the oxidizer side, then get across the stagnation plane (case12). $\mathrm{C}_{6} \mathrm{H}_{5} \mathrm{CH}_{3}$ is mainly generated by $\mathrm{R} 10$ and $\mathrm{R} 11$. However, the consumption of $\mathrm{C}_{6} \mathrm{H}_{5} \mathrm{CH}_{3}$ also substantially exists in the reaction region of $\mathrm{R} 10$, such as $\mathrm{R} 13$ and the reverse reaction of R11. Referred to Fig.5, the accumulation of $\mathrm{C}_{6} \mathrm{H}_{5} \mathrm{CH}_{3}$ is mainly from R11. As a result, the trend of Fig.5 can be attributed to the following two aspects. On the one hand, the ROP of R10 and R11 gradually increased, and finally had a slight decrease, the overall positive $\mathrm{ROP}$ of $\mathrm{C}_{6} \mathrm{H}_{5} \mathrm{CH}_{3}$ is increasing. On the other hand, the rate of R13, also increased significantly, and finally the reacting region of R13 is almost the same as $\mathrm{R} 10$ and $\mathrm{R} 11$, therefore, the accumulation of $\mathrm{C}_{6} \mathrm{H}_{5} \mathrm{CH}_{3}$ decreases. As a result, the increase of the reactions described above and the moving of the flame plane makes the peak of $\mathrm{C}_{6} \mathrm{H}_{5} \mathrm{CH}_{3}$ increase first and then decrease. By the same ROP analysis, $\mathrm{C}_{6} \mathrm{H}_{5} \mathrm{CH}_{2}$ in $\mathrm{R} 11$ was generated by R12, as shown in Table 1 (R10-R13). Referred to R10, it can be seen that $\mathrm{C}_{6} \mathrm{H}_{5} \mathrm{CH}_{3}$ is generated mainly by the combination of $\mathrm{A} 1-$ and $\mathrm{CH}_{3}$. Thus the production of $\mathrm{CH}_{3}$ need to be analyzed.

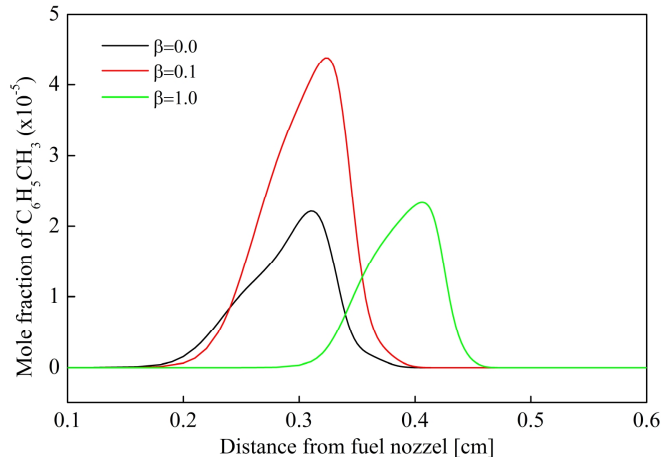

Fig.5. $\mathrm{C}_{6} \mathrm{H}_{5} \mathrm{CH}_{3}$ distribution.

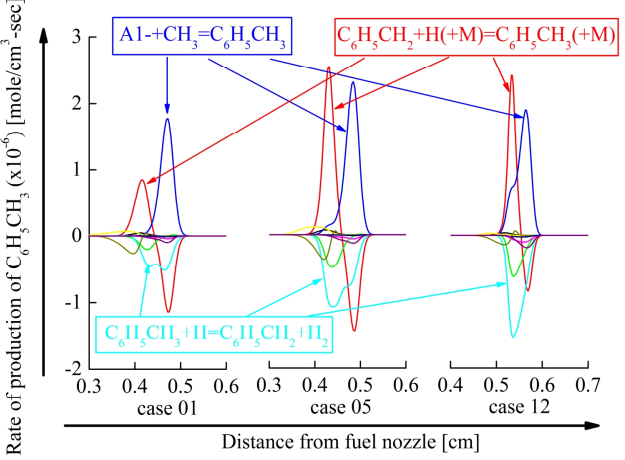

Fig.6. Rate of production analysis of $\mathrm{C}_{6} \mathrm{H}_{5} \mathrm{CH}_{3}$.

Fig. 7 shows the distribution of $\mathrm{CH}_{3}$ in case 01 , case 05 , and case12. The mole fraction of $\mathrm{CH}_{3}$ in the combustion of pure $\mathrm{C}_{2} \mathrm{H}_{4}$ is a single-peak curve, but turns into bimodal curves when heptane is added. And the distribution curve moves towards the oxidizer side with the increasing of $\beta$. Referred to the 
reacting region of Fig.6, the increase of ROP of R11 has close correlation with the first peak in the bimodal curve of $\mathrm{CH}_{3}$.

Fig. 8 shows the ROP of $\mathrm{CH}_{3}$ in these three cases. On the basis of Fig.7, the first peak of $\mathrm{CH}_{3}$ is from the pyrolysis reaction of propyl $\left(n-\mathrm{C}_{3} \mathrm{H}_{7}\right)$, the reverse reaction of $\mathrm{R} 14$. The reacting region of R14 (shown in table 1) is the same as the reaction of R10 and R11, which forms $\mathrm{C}_{6} \mathrm{H}_{5} \mathrm{CH}_{3}$. Thus it can be concluded that the pyrolysis of propyl can increase the ROP of $\mathrm{C}_{6} \mathrm{H}_{5} \mathrm{CH}_{3}$.

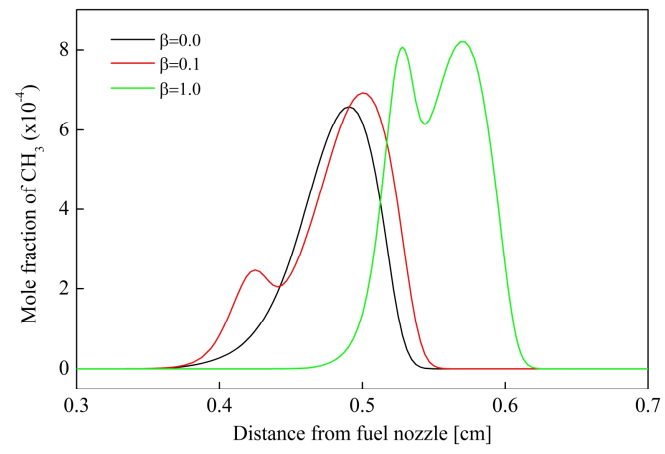

Fig.7. $\mathrm{CH}_{3}$ distribution.

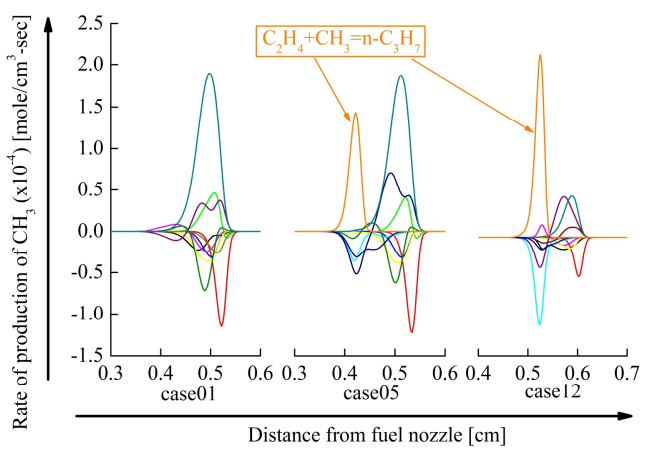

Fig.8. Rate of production analysis of $\mathrm{CH}_{3}$.

Table 3 Main pyrolysis pathway of heptane

\begin{tabular}{l|c}
\hline \multicolumn{1}{c|}{ Key reactions } & Rate \\
\hline $\mathrm{nC}_{7} \mathrm{H}_{16}+\mathrm{H} / \mathrm{OH} / \mathrm{O} / \mathrm{HO}_{2} / \mathrm{CH}_{3}=>\mathrm{C}_{7} \mathrm{H}_{15}+\mathrm{H}_{2} / \mathrm{H}_{2} \mathrm{O} / \mathrm{OH} / \mathrm{H}_{2} \mathrm{O}_{2} / \mathrm{CH}$ & $90 \%$ \\
\hline $\mathrm{C}_{7} \mathrm{H}_{15}=>\mathrm{C}_{2} \mathrm{H}_{4}+\mathrm{C}_{5} \mathrm{H}_{11}-1$ & $47 \%$ \\
\hline $\mathrm{C}_{5} \mathrm{H}_{11}-1=>\mathrm{C}_{2} \mathrm{H}_{4}+\mathrm{n}_{-} \mathrm{C}_{3} \mathrm{H}_{7}$ & $47 \%$ \\
\hline $\mathrm{n}-\mathrm{C}_{3} \mathrm{H}_{7}=\mathrm{C}_{2} \mathrm{H}_{4}+\mathrm{CH}_{3}$ & $43 \%$ \\
\hline
\end{tabular}

The main pyrolysis pathway of heptane is listed in Table 3 by ROP analysis, where the data in the second column represent the conversion percentage of heptane. Through the table, it can be seen that the pyrolysis of heptane greatly increases the concentration of propyl and hence methyl in the flame.

In summary, after adding heptane in the ethylene flame, the pyrolysis of heptane generates a large number of propyl, and then, propyl decomposes to produce $\mathrm{CH}_{3}$, which forms the first peak in the bimodal curve of $\mathrm{CH}_{3}$. Furthermore, $\mathrm{CH}_{3}$ reacts with $\mathrm{A} 1$ - to form $\mathrm{C}_{6} \mathrm{H}_{5} \mathrm{CH}_{3}$, and finally the peak mole fraction of A1 increases by reaction R8. On the other hand, since the ignition delay of heptane is longer than $\mathrm{C}_{2} \mathrm{H}_{4}$, the reacting region moves towards the oxidizer side, resulting a consumption of large number of intermediate key species. The overall influence makes the peak mole fraction of A1 and further PAHs increase first and then decrease.

\section{Conclusions}

Numerical simulations were carried out in a premixed heptane flame, an opposed-flow ethylene/air flame and an opposed-flow ethylene-heptane binary mixture flame, the results are shown as follows.

(1) In the premixed heptane flame and the opposed-flow ethylene/air flame, the concentrations of key components fit well with the experimental data from literatures, which indicates the newly coupled mechanism is highly accurate for predicting the distribution of key species.

(2) In the ethylene-heptane opposed-flow flame, as $\beta$ increases, the soot volume fraction, soot number density, concentration of benzene and maximum points of $\mathrm{PAH}$ all increase first and then decrease.

(3) As $\beta$ increases, the formation regions of benzene and PAH move towards the oxidizer nozzle. The formation and consumption rate both decrease as the reaction region get across the stagnation plane.

(4) Propyl and methyl play important roles in the synergistic effect of the formation of soot, and PAHs. 


\section{Acknowledgment}

This work was financially supported by the National Natural Science Found of China (51576083).

\section{References}

[1] K. T. Kang, J. Y. Hwang, S. H. Chung, and W. Lee, Combustion and Flame, 109 (1997) 266-281.

[2] Hwang J Y, Chung S H et al. Symposium (International) on Combustion, 27(1) (1998) 1531-1538.

[3] Hwang J Y., et al. Combustion and flame, 114(3) (1998) 370-380.

[4] Lee, S.M., S.H. Chung, Combustion and Flame, 136(4) (2004) 493-500.

[5] Yoon, S.S., S.M. Lee and S.H. Chung, Proceedings of the Combustion Institute, 30(1) (2005) 1417-1424.

[6] Yoon, S.S., D.H. Anh and S.H. Chung, Combustion and Flame, 154(3) (2008) 368-377.

[7] Liu, F., et al., Combustion and Flame, 158(3) (2011) 547-563.

[8] Wang, Y. et al., Combustion and Flame, 162(3) (2015) 586-596.

[9] Pitz, W.J. and C.J. Mueller, Progress in Energy and Combustion Science, 37(3) (2011) 330-350.

[10]Kee R J, Rupley F M, Meeks E, et al. Sandia National Laboratory Technical, Report, SAND96-8216, 1996.

[11] Marchal, C., et al., Proceedings of the Combustion Institute, 32(1) (2009) 753-759.

[12] http://ignis.usc.edu/USC Mech II.htm, May 2007.

[13]Jin, H., et al., Combustion and Flame, 162(5) (2015) 1692-1711.

[14] Slavinskaya, N., et al., Combustion and Flame, 159(3) (2012) 979-995.

[15]Raj, A., et al., Combustion and Flame, 159(2) (2012) 500-515.

[16]Wang, Y., A. Raj and S.H. Chung, Combustion and Flame, 160(9) (2013) 1667-1676.

[17] Skeen, S.A., et al., Journal of Aerosol Science, 58(0) (2013) 86-102.

[18]Appel J, Bockhorn H, Frenklach M, Combustion and Flame, 121 (1) (2000) 122-136.

[19]Frenklach M, Wang H, Symposium (International) on Combustion, 23 (1) (1991) 1559-1566.

[20]Frenklach, M. and S.J. Harris, Journal of Colloid and Interface Science, 118(1) (1987) 252-261.

[21]Bakali A E., et al., Combustion Science and Technology, 140(1-6) (1998) 69-91.

[22]N. Olten, S.M. Senkan, Combustion and Flame, 118 (1999) 500-507. 